\title{
$>$ O domínio da arte no pensamento de Hannah Arendt
}

> The realm of art in Hannah Arendt's thought

\section{por Thiago de Castro Leite}

Doutorando em Educação e Mestre em Educação pela Faculdade de Educação da USP, é graduado no curso de Licenciatura em Artes Cênicas da Escola de Comunicações e Artes da USP. Professor Colaborador do Departamento de Artes Cências do CEART-UDESC (Florianópolis-SC), atua também como Professor no Setor de Artes Cênicas do Conservatório de Tatuí (Tatui-SP). E-mail: thiago.castroleite@gmail.com. ORCID: 00000003-1806-7353.

\section{Resumo}

Este artigo propõe uma reflexão acerca do domínio da arte na perspectiva de Hannah Arendt. A partir da análise do pensamento da autora, de seus esforços em problematizar a relação dos homens com o âmbito da arte e das inúmeras vezes em que convoca produções artísticas para examinar a experiência humana no mundo, vislumbra-se identificar as especificidades atribuídas por ela às linguagens artísticas, bem como compreender a relevância da arte na constituição de um legado humano material, imaterial e simbólico, um mundo de significados compartilhados.

Palavras-chave: Domínio da arte. Linguagens artísticas. Hannah Arendt.

\begin{abstract}
This work proposes a reflection about the domain of art from Hannah Arendt's perspective. Based on analysis of the author's thought, of her efforts to problematize the relation of humans to the realm of art, or even of the numerous times in wich she summons up artistic productions to examine the human experience in the world, this article intends to identify the specificities attributed by Hannah Arendt to the artistic language, as well as to understand the relevance of art in the constitution of a material and symbolic human legacy, a world of shared meanings.
\end{abstract}

Keywords: Art domain. Artistic language. Hannah Arendt. 


\section{Sobre o domínio da arte e suas modalidades artísticas}

Embora o domínio da arte não seja o principal foco das reflexões de Hannah Arendt ${ }^{1}$, chama-nos a atenção, em sua obra, as inúmeras referências à pintura, à literatura, à música e ao teatro. Em Origens do Totalitarismo (1989), Arendt evoca Conrad e Kipling para examinar o imperialismo. A peça teatral $O$ Vigário, de Rolf Honchhuth, dá nome e principia sua reflexão em $O$ vigário: culpa pelo silêncio?, ensaio publicado na coletânea Responsabilidade e Julgamento (2004) em que a autora critica o silêncio do papa Pio XII em face das atrocidades de Hitler. Na obra Homens em tempos sombrios (2008b), Arendt recorre a Kafka e Homero para refletir sobre a vida de Walter Benjamin. No prefácio de Entre o passado e o futuro (2009) compara a unidade dos capítulos desse trabalho a uma suíte musical e, ainda na mesma obra, no ensaio "A crise na educação", ao refletir sobre a responsabilidade - de conservação e renovação do mundo comum - que cada nova geração deve tomar para si, evoca a célebre frase de Hamlet: "O tempo está fora dos eixos. Ó ódio maldito ter nascido para colocá-lo em ordem”2.

Bérénice Levetdenomina essas constantes referências como uma espécie de "museu imaginário"3 arendtiano, uma vez que, em seus exercícios de pensamento, Arendt preferiria a companhia de criadores de produções artísticas, como Homero e Virgílio, Shakespeare e Dante, Goethe e Rilke, Ibsen ou Strindberg, Haendel e Rembrandt, à de especialistas nas ciências humanas e sociais. Afinal, para ela, as obras desses autores tinham a capacidade de explorar e iluminar poeticamente a realidade do mundo humano, tornando acessível aos outros homens e mulheres aquilo que, por serem parte integrante dessa realidade, não conseguiam enxergar.

\footnotetext{
${ }^{1}$ As reflexões de Arendt, em geral, dizem respeito à relação dos homens entre si e com o mundo que habitam e são frequentemente tratadas no âmbito da política e da filosofia. Por isso, existem ainda poucas pesquisas e estudos que examinam seu pensamento dando atenção ao domínio da arte, como Cambier, 2007; Levet, 2011 e Lamas, 2015.

${ }^{2}$ Hannah Arendt, Entre o passado e o futuro, 2009, p. 242.

${ }^{3}$ Bérénice Levet, Le musée imaginaire d'Hannah Arendt, 2011.
} 
Entretanto, Arendt evoca o âmbito das produções artísticas não somente como forma de exemplo para elucidação de outros conceitos, mas, também, em determinados momentos, como uma questão específica a ser examinada. Assim o faz em A condição humana (2010), obra na qual dedica um espaço para refletir sobre a obra de arte e sua permanência no mundo ou, ainda, em seu ensaio A crise da cultura: sua importância social e política ${ }^{4}$, no qual examina como a crise do mundo moderno acabou interferindo no modo como nos relacionamos com a arte e, consequentemente, com o mundo.

Se visitarmos outros de seus escritos, podemos ainda verificar mais e mais alusões ao domínio da arte, desde discussões sobre o que inspira a criação de obras de arte até reflexões sobre o lugar que ocupam no mundo, como em $A$ vida do espírito (2014), obra em que Arendt examina a relação entre pensamento, linguagem e metáfora, ou nos textos dedicados a Isak Dinesen, Hermann Broch e Bertolt Brecht, na já citada obra Homens em Tempos Sombrios.

Em suma, ao longo de sua obra, Hannah Arendt confere aos produtos artísticos um lugar especial em sua concepção acerca do mundo e do vínculo que com ele estabelecemos, e isso do ato de criação à exibição pública, do pensamento que inspira essa criação à reflexão gerada por ela. Para a autora, como maiores testemunhas do mundo humano, as criações artísticas reafirmam a existência de um passado, examinam os acontecimentos do presente, podem tornar-se vestígios imorredouros das ações e realizações humanas e, potencialmente, possibilitam que, com sua fruição, os homens reconciliem-se com a realidade em que vivem, sentindo-se menos estrangeiros no mundo que habitam.

Diante dessas recorrentes referências e reflexões feitas por Arendt, nos parece oportuno perguntar como e de que modo, aos olhos da autora, o domínio da arte se constitui.

\footnotetext{
${ }^{4}$ Hannah Arendt, A crise da cultura: sua importância social e política, In Hannah Arendt, Entre o passado e o futuro, 2009.
} 
No intento de responder a essa questão, nos detemos, especificamente, sobre a distinção realizada por Arendt acerca das modalidades pertencentes ao domínio da arte, ou seja, as formas pelas quais os produtos artísticos se manifestam: através dos objetos de arte - fabricados como artefatos materiais, como na pintura, na escultura ou na arquitetura - e das artes performáticas ${ }^{5}$ cuja obra refere-se à execução pública de uma atividade, como no caso da dança, com movimentos corporais; da música, com o tocar um instrumento, ou do teatro, com gestos e a palavra. Por vezes, em seus escritos, essas duas formas são chamadas por um denominador comum: a obra de arte ${ }^{6}$.

\section{Os objetos de arte}

Para Arendt, os objetos de arte ligam-se mais à atividade da fabricação. A fabricação diz respeito à capacidade humana de criar objetos duráveis que garantem a constituição de um mundo dotado de relativa estabilidade, no qual transcorre a existência humana - uma forma de vida que transcende o mero metabolismo com a natureza. A fabricação oferece, também, a possibilidade de os homens lograrem criar algo mais permanente do que sua existência vital, obras que possam perdurar por um tempo maior que a efemeridade da vida de seus autores. Dando forma à matéria-prima - a madeira, a argila, o ferro, por exemplo - os homens vão construindo inúmeros artefatos, coisificando a própria matéria da natureza. Esses artefatos, uma vez tendo adentrado o mundo humano, são

\footnotetext{
${ }^{5}$ Arendt distingue os produtos artísticos em duas categorias específicas: creative arts of making e performing arts. Embora na tradução de suas obras para o português esses termos possam aparecer grafados de outra maneira, como artes criativas de fabricação e artes de realização (Cf. Hannah Arendt, Entre o passado e o futuro, 2009, p. 200), optamos por denominá-los, aqui, respectivamente, como objetos de arte e artes performáticas.

${ }^{6}$ Apesar do termo obra de arte estar ligado à forma específica dos objetos artísticos, por vezes Arendt dirige-se, também, às artes performáticas, como na seguinte afirmação: "dentre as obras de arte, a que menos é uma coisa é um poema" (Hannah Arendt, A condição humana, 2010, p. 212). A fim de evitar possíveis confusões referentes ao uso desses termos em nossa explanação, referiremo-nos à criação artística, de modo geral, como produtos ou produções artísticas e às formas específicas citadas, como objetos de arte ou artes performáticas.
} 
tomados a partir de duas modalidades distintas de relação: ou servem para o uso, deteriorando-se à medida que essa utilização os desgasta, ou são retirados do ciclo de uso e consumo e, conservados, ganham o espaço público, como os objetos de arte.

Aquele que fabrica a obra - o homo faber, que no âmbito da arte se apresenta como artista - normalmente afasta-se da publicidade do mundo durante o processo de fabricação, distanciando-se dos outros para ter um encontro com o material que será transformado. É nesse encontro, entre artista e matéria, que se dá num âmbito protegido do mundo público, que os objetos de arte ganham forma, peso, solidez. Assim como um artesão transforma a madeira em uma cadeira, o couro em um sapato, o artista transforma uma infinidade de materiais num artefato, um objeto artístico que nasce para ser visto, cuja fonte imediata é a capacidade de pensar.

\section{Para Arendt:}

As obras de arte são frutos do pensamento, mas nem por isso deixam de ser coisas. O processo de pensamento não é capaz de produzir e fabricar por si próprio coisas tangíveis, como livros, pinturas, esculturas ou composições, da mesma forma como o uso é incapaz de produzir e fabricar por si próprio casas e móveis. Naturalmente, a reificação que ocorre quando se escreve algo, quando se pinta uma imagem ou se modela uma figura ou se compõe uma melodia, tem a ver com o pensamento que a precede; mas o que realmente transforma o pensamento em realidade e fabrica as coisas do pensamento é a mesma manufatura [workmanship] que, com a ajuda do instrumento primordial que são as mãos humanas, constrói as coisas duráveis do artifício humano. ${ }^{7}$

Embora inspirado pelo pensamento, o objeto artístico não pode ser equiparado a ele ou identificado como seu produto. A solidez e a durabilidade das obras de arte não condizem com os processos que ocorrem na atividade do pensar - que é "tão incessante e repetitiva quanto a própria vida"8, pois está fadada a sempre recomeçar. O pensamento diz respeito ao ato de "examinar o que quer que aconteça ou chame a atenção, independentemente de resultados e conteúdos

\footnotetext{
${ }^{7}$ Hannah Arendt, A condição humana, 2010, p. 213.

${ }^{8}$ Ibidem, p. 214.
} 
específicos" ${ }^{\prime \prime}$, num diálogo interno do sujeito consigo próprio, não tendo outro propósito para além de si mesmo. Desse modo, o pensamento não produz - no sentido material - resultado algum, pois é exatamente a atividade de pensar que o artista interrompe e transforma no ato de criação de sua obra. Segundo Arendt, tanto "a filosofia utilitária do homo faber", quanto "os homens de ação e os entusiastas por resultados nas ciências jamais se cansaram de assinalar quão inteiramente 'inútil' é o pensamento - realmente, tão inútil quanto as obras de arte que inspira"10 ${ }^{\prime}$. Contudo, a constatação de que tanto a obra de arte quanto o pensar são inúteis não implica que eles não sejam relevantes e significativos para a existência humana; simplesmente torna patente que esse significado não deriva de sua utilidade ou aplicabilidade imediata, como no caso de um objeto de uso.

Em certa medida, essa transformação que se dá do pensamento que inspira para o objeto artístico reificado configura-se como uma forma de desregular a natureza. Tal como nos revela, por exemplo, as palavras de Manoel de Barros.

Tentei montar com aquele meu amigo que tem um olhar descomparado, uma Oficina de Desregular a Natureza. Mas faltou dinheiro na hora para a gente alugar um espaço. Ele propôs que montássemos por primeiro a Oficina em uma gruta. Por toda parte existia gruta, ele disse. E por ele logo achamos uma na beira da estrada. Ponho por caso que até foi sorte nossa. Pois que debaixo da gruta passava um rio. O que de melhor houvesse para uma Oficina de Desregular a Natureza! Porque logo fizemos o primeiro trabalho. Era o Besouro de olhar ajoelhado. Botaríamos esse Besouro no canto mais nobre da gruta. Mas a gruta não tinha canto mais nobre. Logo apareceu um lírio pensativo de sol. De seguida um lírio pensativo de chão. Pensamos que sendo o lírio um bem da natureza prezado por Cristo resolvemos dar nome ao trabalho de Lírio pensativo de Deus. Ficou sendo. Logo fizemos a Borboleta beata. E depois fizemos Uma ideia de roupa rasgada de bunda. E A fivela de prender silêncio. Depois elaboramos A canção para a lata defunta. E ainda a seguir: $O$ parafuso de veludo, $O$ prego que farfalha, $O$ alicate cremoso. E por último aproveitamos para imitar Picasso com A moça com olho no centro da testa. Picasso desregulava a natureza, tentamos imitá-lo. Modéstia à parte. ${ }^{11}$

Em sua "oficina de desregular a natureza", a salvo de ser perturbado e de ser visto e ouvido por outros homens, o artista está junto não somente dos

\footnotetext{
${ }^{9}$ Idem, A vida do espírito, 2014, p. 20.

${ }^{10}$ Idem, Op. Cit., 2010, p. 213.

${ }^{11}$ Manoel de Barros, Memórias inventadas: as infâncias de Manoel de Barros, 2010, p. 87.
} 
produtos que fabrica, mas, também, do "mundo de coisas ao qual acrescentará seus próprios produtos", e, assim, ele continua, embora indiretamente, "a conviver com os outros que já fizeram o mundo e também são fabricantes de coisas"12. De modo que as referências que são tomadas para sua criação dizem respeito às experiências vivenciadas por ele no mundo que habita. No texto de Manoel de Barros isso se revela nas denominações de cada obra, como o "parafuso de veludo", o "prego que farfalha" ou o "alicate cremoso" - nomes carregados de significados compartilhados - ou na simples tentativa de "imitar" Picasso.

Os objetos de arte, segundo Arendt, são, por excelência, o que existe de mais mundano entre as criações humanas, ou seja, dos artefatos materiais criados pelos seres humanos que constituem e dão sentido ao mundo que habitamos são aquilo que pode adquirir uma excepcional permanência. Sua durabilidade "permanece quase inalcançada pelo efeito corrosivo dos processos naturais", uma vez que esses objetos não estão sujeitos "ao uso por criaturas vivas"13.

Esses produtos artísticos ocupam um lugar peculiar em relação às atividades humanas, especificamente, por serem - como citado anteriormente inúteis. Inúteis, pois não se equiparam aos resultados do trabalho ${ }^{14}$ - que são produzidos e consumidos quase que instantaneamente e integram o ciclo vital -, tampouco se igualam aos objetos de uso que se desgastam na medida em que são utilizados pelos homens para outros diversos fins. Assim, do ponto de vista da mera utilidade, a atividade do artista que fabrica aproxima-se bem do que encontramos em mais um excerto de Manoel de Barros:

O que eu faço é servicinho à toa. Sem nome nem dente. Como passarinho à toa. $\mathrm{O}$ mesmo que ir puxando uma lata vazia o dia inteiro até a noite por cima da terra. Mesmo que um caranguejo se arrastando pelo barranco à procura de água vem um boi e afasta o rio dele com patas para sempre. $O$ que eu ajo é tarefa desnobre. Coisa de nove noves fora: teriscos, nhame-

\footnotetext{
${ }^{12}$ Hannah Arendt, A condição humana, 2010, p. 260.

${ }^{13}$ Ibidem, p. 209.

${ }^{14}$ Enquanto atividade humana, o trabalho (labor) relaciona-se com o processo vital do homem, com sua luta contínua pela sobrevivência. Por meio dele, o homem produz bens que são consumidos, que garantem a subsistência de cada indivíduo e a perpetuação da espécie, compreendendo, portanto, o metabolismo dos humanos com a natureza. Sobre as atividades humanas do trabalho, da fabricação e da ação, ver Hannah Arendt, A condição humana, 2010.
} 
nhame, de-réis, niilidades, oco, borra, bosta de pato que não serve nem para esterco. ${ }^{15}$

O artista que fabrica volta-se não para as necessidades da vida humana, mas, antes, para aquilo que, segundo o texto de Manoel de Barros, "não serve nem pra esterco". E, uma vez que sua atividade não gera nem um produto para ser consumido ou usado, de determinado ponto de vista realmente é uma "tarefa desnobre". Pois os objetos criados nessa tarefa não têm uma finalidade, não servem para outro fim quando prontos - como uma cadeira é feita para sentar -, mas, diferentemente, adquirem um sentido no mundo à medida que são vistos e fruídos por seus espectadores.

Assim, é exatamente por essa característica, por não gerar coisas para serem usadas ou consumidas, que a atividade do artista possibilita a fabricação de objetos de arte mais duráveis que todas as outras coisas. Objetos que apresentam uma excepcional permanência, compreendida por Arendt como potencial imortalidade. Segundo a autora:

Entre os objetos que não ocorrem na natureza, mas tão-somente no mundo feito pelo homem, distinguimos objetos de uso e obras de arte, os quais possuem ambos uma certa permanência que vai desde a durabilidade ordinária até a potencial imortalidade no caso de obras de arte. ${ }^{16}$

Essa potencial imortalidade se revela nos inúmeros artefatos que ainda restam das mais diversas civilizações. Seja porque enquanto objetos de uso foram protegidos do desgaste de maneira deliberada para, então, perpetuarem ou por serem criações artísticas ${ }^{17}$, em si, inúteis. Produtos artísticos criados pelos povos sobrevivem ao tempo como testemunhas de suas existências. Pinturas rupestres, templos, teatros, mosaicos, esculturas. Dos pré-colombianos aos sumérios, dos gregos aos romanos, dos bizantinos aos renascentistas. O que temos como

\footnotetext{
${ }^{15}$ Manoel de Barros, O livro das pré-coisas, 2007, p. 45.

${ }^{16}$ Hannah Arendt, Entre o passado e o futuro, 2009, p. 262.

${ }^{17}$ As criações artísticas também necessitam de uma conservação deliberada para que possam perdurar no tempo. Esta conservação está inteiramente ligada ao modo como nos relacionamos com essas criações. Portanto, assim como os objetos de uso que foram retirados do ciclo de uso e consumo e tidos como uma testemunha do passado, essa mesma atitude de proteção, que ocorre de maneira deliberada, guia a perpetuação das obras de arte.
} 
referência de grande parte da história do mundo são os objetos de arte que ainda hoje permanecem como legado para as novas gerações.

Assim, vistos a partir da mera durabilidade, esses objetos são "claramente superiores a todas as demais coisas; e, visto ficarem no mundo por mais tempo do que tudo o mais, são o que existe de mais mundano entre todas as coisas"18. Eles não apenas não são consumidos no ciclo vital e gastos como objetos de uso, mas são de forma deliberada removidos e isolados do âmbito das necessidades da vida humana. Pelo contrário, se tomados pela possessividade de indivíduos, podem vir a desaparecer. Segundo Arendt:

\begin{abstract}
Essas coisas, obviamente, partilham com os "produtos" políticos, palavras e atos, a qualidade de requererem algum espaço público onde possam aparecer e ser vistas; elas só podem realizar seu ser próprio, que é a aparição, em um mundo comum a todos; no encobrimento da vida privada e da posse privada, objetos de arte não podem atingir sua própria validez inerente; é forçoso, pelo contrário, que sejam protegidos da possessividade de indivíduos - por isso, não importa que tal proteção assuma a forma de colocá-los em locais sagrados, em tempos e igrejas, ou entregá-los ao cuidado de museus e de zeladores de monumentos, posto que o lugar onde os colocamos seja característico de nossa "cultura", isto é, nosso modo de comunicação com eles. ${ }^{19}$
\end{abstract}

Se escondidos num ambiente privado, os objetos de arte perdem seu sentido primeiro, o de aparecer ao mundo público, que é constituído por outras tantas obras e tecido pela teia de relações humanas. O risco de virar mero adereço de decoração privado despotencializa o que há de mais vigoroso no objeto artístico, sua capacidade de constituir-se como algo compartilhado - por meio da simples relação entre espectador e obra, inerente a qualquer criação. Desse modo, um objeto de arte só existe de fato e pode permanecer no percurso histórico se aparecer no espaço público. Só assim pode ser visto e preservado. Ele tem um papel fundamental na concepção desse espaço, pois é aquilo que pode perpetuar - em face da ida e vinda de novos seres humanos - como testemunha do mundo que temos em comum.

\footnotetext{
${ }^{18}$ Hannah Arendt, Entre o passado e o futuro, 2009, p. 262.

${ }^{19}$ Ibidem, p. 272.
} 
Portanto, para Arendt, os objetos de arte são, por excelência, aquilo que temos de mais mundano entre todas as coisas tangíveis, por isso podem permanecer através das eras e, dessa forma, se perpetuar em face da sucessão de gerações, desde que os homens estabeleçam com eles uma relação apropriada. Por apropriada remetemo-nos a uma forma de relacionar-se com a arte distinta da maneira que tomamos os produtos do trabalho - que são produzidos e consumidos quase que instantaneamente e integram o ciclo vital - e os objetos de uso - que servem como meio para outros fins, como uma caneta para escrever ou uma cadeira para sentar. Antes, refere-se a um tratamento específico que deve ocorrer de maneira compartilhada na "luz do mundo público"20.

Já as linguagens artísticas performáticas, uma vez que não são fabricadas como os objetos de arte ${ }^{21}$, aproximam-se mais da atividade humana da ação. ${ }^{22}$ Seu potencial artístico reside no fato de que um alguém executa uma atividade - seja ela cantar, dançar, atuar ou tocar um instrumento - e o virtuosismo de seu desempenho é contemplado por um público de espectadores.

\section{As artes performáticas}

Embora as produções artísticas performáticas precisem também de um espaço não-público para serem preparadas, elas não dizem respeito à constituição de uma coisa, ou seja, algo material que ganha forma à medida que seu criador, o homo faber, opera sobre a matéria da natureza. Portanto, não se constituem na

\footnotetext{
${ }^{20}$ Por "luz do mundo público" identificamos aqui o espaço da ação, da teia das relações humanas, em que, assim como em um palco, "tudo que aparece em público pode ser visto e ouvido por todos e tem a maior divulgação possível" (Hannah Arendt, A condição humana, 2010, p. 61).

${ }^{21}$ Ressaltamos que Arendt, ao examinar o domínio da arte, não se debruça a pensar sobre as produções artísticas que transitam entre a durabilidade dos objetos de arte e a efemeridade das artes performáticas, como instalações ou intervenções urbanas. Neste trabalho optamos por não adentrar essa discussão. Para conferir uma reflexão acerca dessa lacuna no pensamento da autora, ver: Lamas, 2015.

${ }^{22}$ A atividade da ação (action), é a única que se dá diretamente entre os homens, sem a intermediação de coisas ou da matéria, "corresponde à condição humana da pluralidade", ao fato de que os homens, no plural, "vivem na Terra e habitam o mundo" (Hannah Arendt, A condição humana, 2010, p. 8). A ação corresponde, também, à capacidade de interagirem entre si e desencadearem o novo, ou seja, constitui o âmbito da política.
} 
materialidade de objetos físicos que podem ser vistos mesmo sem a presença de seu criador. Nessas artes performáticas o que aparece ao mundo não é uma coisa a ser fruída por espectadores, mas um alguém em atividade. Seu "material" consiste em sons, gestos e palavras, e "a reificação e a manufatura (workmanship) necessárias são mínimas"23. Tomemos como referência um trecho do conto "O artista da fome" de Franz Kafka:

\begin{abstract}
Naquela época a cidade inteira se ocupava com o artista da fome; a cada dia de jejum o público aumentava; todos queriam ver o artista da fome pelo menos uma vez por dia; nos últimos dias havia quem passasse o dia inteiro sentado diante da pequena jaula; à noite também havia visitação, à luz de tochas, para aumentar o efeito; nos dias bonitos a jaula era transportada ao ar livre, e então eram principalmente às crianças que exibiam o artista da fome, enquanto para os adultos ele não era mais do que um passatempo, com o qual se entretinham porque era moda, as crianças olhavam-no impressionadas, de boca aberta, com as mãos dadas para vencer o temor, enquanto o homem, pálido, vestindo um abrigo escuro, com costelas muito protuberantes, desprezando até mesmo uma cadeira, ficava sentado na palha, com um aceno polido de cabeça, respondia perguntas com um sorriso forçado e estendia o braço por entre as barras, para que pudessem sentir com as mãos sua magreza, quando então ele se recolhia uma vez mais em si mesmo, não se preocupava com mais ninguém, nem mesmo com as graves badaladas do relógio, que era o único móvel no interior da jaula, mas apenas olhava para o vazio com os olhos semicerrados e de vez em quando bebericava um gole d'água para umedecer os lábios. ${ }^{24}$
\end{abstract}

O que Kafka nos descreve não é um objeto definido, mas características especificamente humanas que se dão nos atos e realizações do artista que executa uma determinada atividade. $\mathrm{O}$ artista da fome nada mais faz que jejuar, nessa tarefa realiza pequenos gestos, alguns movimentos e, mesmo em silêncio, comunica uma série de significações àqueles que o observam. Os produtos de sua arte são verbos e não substantivos, isto é, são realizações, como: "ficar sentado na palha, responder perguntas com um sorriso forçado e estender o braço por entre as barras". Talvez possamos dizer que uma certa materialidade de sua exibição reside em seu próprio corpo e nas características que lhe são inerentes, a "figura do homem pálido, vestindo um abrigado escuro e com costelas protuberantes". Assim, o que o espectador vê não são objetos criados pelas mãos de um alguém que fabrica, mas o desempenho de um artista. De modo que no texto de Kafka

\footnotetext{
${ }^{23}$ Hannah Arendt, A condição humana, 2010, p. 212.

${ }^{24}$ Franz Kafka, O artista da fome, 2013, p. 373.
} 
"todos queriam ver o artista da fome pelo menos uma vez por dia", e não somente os objetos que dispunha na jaula.

Esta peculiaridade inerente a toda arte performática é que a aproxima da atividade da ação. Diferentemente da fabricação, a ação não produz um objeto, mas possibilita a constituição de narrativas, relatos e histórias, à medida que a existência de cada ser humano que age - composta por suas obras, seus atos e palavras - pode ser lembrada; portanto, ela se dá no encontro dos homens no mundo. Segundo Arendt, a afinidade das formas artísticas performáticas com a ação reside no fato de que,

[...] os artistas executantes - dançarinos, atores, músicos e o que o valha precisam de uma audiência para mostrarem seu virtuosismo, do mesmo modo que os homens que agem necessitam da presença de outros ante os quais possam aparecer; ambos requerem um espaço publicamente organizado para sua "obra", e ambos dependem de outros para o desempenho em si. ${ }^{25}$

Embora estejam em esferas distintas - pois enquanto a exibição de um artista tem uma duração prevista, um momento em que começa e que termina, o fim da ação é imprevisível -, ambas se aproximam devido à necessidade de ocorrerem na pluralidade dos homens.

A execução de um artista quando este está só, sem um público de espectadores, nada mais é do que um ensaio, uma repetição que vislumbra o aprimoramento técnico da arte que realiza, seja na dança, na música ou no teatro. Do mesmo modo, os homens e mulheres só são capazes de agir porque compartilham com outros seres singulares um mundo comum. É por isso que Arendt, ao tratar da ação, frequentemente faz referência a uma peça de teatro, onde os humanos - tendo como palco de seus atos e palavras o mundo interagem entre si e podem ser vistos e ouvidos por seus pares, outros espectadores.

\footnotetext{
${ }^{25}$ Hannah Arendt, Entre o passado e o futuro, 2009, p. 200.
} 
A aproximação que Arendt faz das artes performáticas com a ação ainda reside em outro aspecto, o modo pelo qual ambas podem permanecer no mundo através da lembrança. Ouvir a execução de uma bela canção, admirar-se por movimentos virtuosos de um bailarino ou emocionar-se com as palavras de uma atriz só podem continuar a existir por meio das lembranças daqueles que acompanharam, como espectadores, seu desempenho. Ainda assim, ressaltamos: cada uma das linguagens artísticas que ocorre de modo performático guarda um elemento de fabricação.

Para além das lembranças, esse elemento é a única parte que pode resistir à efemeridade da vida humana, garantindo uma certa durabilidade a essas modalidades artísticas. Tomemos como exemplo as tragédias de Ésquilo, Sófocles e Eurípides. Embora não tenhamos a dimensão da experiência performática da tragédia na Grécia antiga, é-nos possível, através da leitura de seus vestígios imorredouros, sua literatura dramática, reconhecê-la como parte integrante e testemunha de um mundo que habitamos. Esses vestígios fabricados são os que permanecem, assim como uma partitura musical de uma sinfonia de Beethoven pode ser executada nos dias de hoje ou as técnicas de movimentos centenárias do balé clássico realizadas por virtuosos bailarinos contemporâneos. Arendt afirma que,

[...] mesmo um poema, não importa quanto tempo tenha existido como viva palavra falada na lembrança do bardo e dos que o escutaram, será finalmente "feito", isto é, escrito e transformado em uma coisa tangível entre as coisas, pois a recordação e o dom da lembrança, dos quais provém todo desejo de imperecibilidade, necessitam de coisas que os façam rememorar, para que eles próprios não venham a perecer. ${ }^{26}$

Portanto, as artes performáticas, apesar de só ocorrerem enquanto um artista se põe a realizar alguma atividade, exibindo-se publicamente, ainda assim guardam um aspecto de fabricação que permanece como vestígio imorredouro. No quadro do pensamento arendtiano as duas modalidades de manifestação da arte - os objetos artísticos e as artes performáticas - compreendem, então,

\footnotetext{
${ }^{26}$ Hannah Arendt, A condição humana, 2010, p. 212.
} 
algumas características fundamentais: primeiramente, não são criadas para serem usadas, no sentido dos inúmeros utensílios fabricados por mãos humanas para um outro fim que não o de aparecer. Afinal, não usamos um quadro impressionista para inserir um prego na parede ou para sustentar uma mesa. Em segundo lugar, o domínio da arte proporciona a constituição de um espaço compartilhado, uma vez que toda criação artística necessita de um lugar público em que possa ser vista por outros seres singulares. Tanto os objetos artísticos fabricados, quanto as artes performáticas só podem adquirir seu real status artístico se aparecerem para outros, para homens e mulheres que os identifiquem e os reconheçam como tal.

\section{Considerações finais}

Ao longo desse percurso reflexivo e das distinções até aqui realizadas, pudemos perceber um modo de compreensão da arte pautado na experiência pública que ela proporciona, na capacidade de criar um espaço-entre, onde os humanos podem se encontrar em torno de algum comum. Nesse sentido, toda modalidade artística, seja ela um objeto fabricado ou o desempenho de um artista performático, diz respeito a um mundo comum. Um lugar em que, enquanto seres singulares, habitamos e partilhamos. Logo, é sempre a partir das experiências que temos nesse espaço que os produtos artísticos são criados e, consequentemente, sobre o que dizem respeito.

Ainda que o esforço de Arendt em compreender as distintas esferas da existência humana revele um ponto de vista singular sobre o domínio da arte, ele provavelmente não encerra as possibilidades de problematização das relações tecidas entre homens e mulheres e as criações artísticas que integram o legado material, imaterial e simbólico do mundo. Todavia, ao dedicar-se ao exercício do pensar, procurando insistentemente examinar o contexto no qual estava inserida, Hannah Arendt nos inspira a pôr em questão as experiências que compartilhamos com tantos outros sujeitos e, no que toca o âmbito da arte, nos 
indagar sobre nossos modos de relação com as inúmeras produções artísticas que fruímos e criamos na contemporaneidade.

Por fim, ao reconhecer a relevância dada pela autora ao domínio da arte e às especificidades de cada modalidade que a constitui, quiçá possamos também identificar as produções artísticas como elementos fundamentais de nosso viver juntos em comunidade, como testemunhas de experiências simbólicas compartilhadas e de criação de vínculos entre as gerações que nos antecederam e as que virão depois de nós.

\section{Referências}

ARENDT, Hannah. A condição humana. Rio de Janeiro: Forense Universitária, 2010.

ARENDT, Hannah. A vida do espírito. Rio de Janeiro: Relume Dumará, 2014.

ARENDT, Hannah. Compreender: formação, exílio e totalitarismo. São Paulo: Companhia das Letras; Belo Horizonte: Editora UFMG, 2008 .

ARENDT, Hannah. Entre o passado e o futuro. São Paulo: Perspectiva, 2009. ARENDT, Hannah. Homens em tempos sombrios. São Paulo: Cia das Letras, 2008b.

ARENDT, Hannah. Responsabilidade e Julgamento. São Paulo: Cia das Letras, 2004.

ARENDT, Hannah. Origens do Totalitarismo. São Paulo: Companhia das letras, 1989.

BARROS, Manoel. Livro de pré-coisas: roteiro uma excursão poética no Pantanal. Rio de Janeiro: Record, 2007. 
BARROS, Manoel. Memórias inventadas: as infâncias de Manoel de Barros. São Paulo: Editora Planeta do Brasil, 2010.

CAMBIER, Alain. Hannah Arendt: la part de l'art dans la constitution d'un monde commun d'apparence. In : Apparence(s) - Revue Eletronique. Lille, Université de Lille 3, vol. 1, 2007. Disponível em: <http://apparences.revues.org/56>. Acesso em: 10 mai. 2019.

GOMBRICH, E. H. A História da Arte. Rio de Janeiro: LTC, 2009.

KAFKA, Franz. Obras Escolhidas. Porto Alegre: L\&PM, 2013.

LAMAS, Anyele Giacomelli. Por um sentido formativo da arte numa "sociedade de consumidores": uma inserção no pensamento político de Hannah Arendt e de Jacques Rancière. 2015. 104f. Dissertação (Mestrado em Educação). Faculdade de Educação, Universidade de São Paulo, São Paulo, SP.

LEITE, Thiago de Castro. Teatro como experiência formativa: um diálogo com o pensamento de Hannah Arendt. 2016. 112f. Dissertação (Mestrado em Educação). Faculdade de Educação, Universidade de São Paulo, São Paulo, SP.

LEVET, Bérénice. Le musée imaginaire d'Hannah Arendt. Paris: Stock, 2011.

SHAKESPEARE, William. Hamlet. São Paulo: Peixoto Neto, 2004.

YUNG-BRUEHL, Elisabeth. Por amor ao Mundo. Rio de Janeiro: Relume Dumará, 1997.

\section{Referência para citação deste artigo}

LEITE, Thiago. O domínio da arte no pensamento de Hannah Arendt. Revista PHILIA |Filosofia, Literatura \& Arte, Porto Alegre, volume1, número 2, p. 548 -563, outubro de 2019. 